Año 11.

Revista de Investigación

Núm. 28

Académica sin Frontera

ISSN: 2007-8870

\title{
http://revistainvestigacionacademicasinfrontera.com
}

\section{Estructura factorial exploratoria de las expectativas hacia grupos cercanos a portadores del VIH/SIDA}

\section{Exploratory factor structure of expectations towards groups close to HIV / AIDS carriers}

\section{Cruz García Lirios ${ }^{1}$}

Resumen -Las disposiciones hacia el VIH / SIDA han sido ampliamente estudiadas desde la perspectiva de quien porta el virus o quien está enfermo, o bien, desde la óptica de quienes pertenecen a los grupos de portadores o desde quienes desean adscribirse, pero en un sentido diferente el presente trabajo se propuso estudiar a individuos que interactúan con grupos cercanos a portadores con la finalidad de establecer la consistencia interna y la convergencia de dimensiones de un instrumento que midió las expectativas y que a partir de un estudio no experimental y una selección no probabilística 258 estudiantes de una universidad pública, encontró tres dimensiones preponderantes que la literatura conceptualizó previamente como expectativas hacia la identidad, el estigma y la utilidad, pero que no había podido contrastar empíricamente.

Palabras claves -identidad, estigma, expectativas, confiabilidad, validez

${ }^{1}$ CEPS, Cuernavaca: garcialirios@aol.com 


\title{
http://revistainvestigacionacademicasinfrontera.com
}

\begin{abstract}
The provisions for HIV / AIDS have been widely studied from the perspective of who carries the virus or who is sick, or from the point of view of those who belong to the groups of carriers or from whom they wish to join, but in a sense different the present work was proposed to study individuals who interact with groups close to carriers with the purpose of establishing the internal consistency and the convergence of dimensions of an instrument that measured the expectations and that from a non-experimental study and a nonprobabilistic selection 258 students of a public university, found three preponderant dimensions that the literature previously conceptualized as expectations towards identity, stigma and utility, but that had not been able to contrast empirically.
\end{abstract}

Keywords -identity, stigma, expectations, reliability, validity

\section{Introducción}

En el marco de las políticas de salud, los procesos psicológicos de identidad y estigma son un binomio que trata de explicar procesos de evaluación de estilos de vida relacionadas con grupos vulnerables. Precisamente, el objetivo del presente trabajo es establecer la validez y confiabilidad de un instrumento que midió ambas dimensiones en una escala de expectativas (García, 2018).

El Virus de Inmunodeficiencia Humana (VIH) es un problema de salud pública debido al proceso de incubación y desarrollo. El ciclo del VIH comprende un periodo estándar de 10 años en los que los infectados siguen teniendo estilos de vida riesgosos, ya que no modifican su comportamiento debido a un síntoma que los obligue al autocuidado (Bautista, Aldana y García, 2018).

El proceso de contagio y reinfección es más probable, ya que desde que la membrana plasmica y el receptor CD4 son infectados, hasta que se procesa el ARN vírico y se 


\section{http://revistainvestigacionacademicasinfrontera.com}

reconstruye el nuevo virón, los diagnósticos no son concluyentes y prolifera el contagio del virus en personas con conductas de riesgo (García, Delgado y García, 2018).

De este modo, el ciclo del VIH parece evidenciar estilos de vida de riesgo que es posible observar en cualquier parte del mundo y que podrían estar asociados a expectativas en torno a los portadores, así como a los grupos a los que pertenecen (Anguiano, Aldana, Valdés, Delgado y García, 2018).

De esta manera, 30,1 millones de casos son de adultos, 16,8 millones de mujeres y 1,5 millones de niños. África Subsahariana tiene el mayor número de portadores con 22’900,000 mientras que el Norte de África registra 470 mil casos. En América Latina existen 1,5000 mil portadores y en México sólo 200 mil casos (Vilchis, Velez y García, 2018).

Ambos aspectos, el proceso de infección y el aumento desproporcionado en las regiones parecen indicar que el problema tiene su origen en las conductas de riesgo mismas que al ser influidas por la identidad de grupos portadores y no portadores convierten al VIH en un problema de salud pública relativo al estigma (Quintero, Valdés, Delgado y García, 2018).

En ciencias de la salud, los grupos cercanos a enfermos son conocidos como soporte social y son factor preponderante en la adherencia al tratamiento, principal variable determinante de la salud hospitalaria (Davis, Shell y King, 2012). En el caso de los grupos cercanos a portadores de VIH/SIDA no sólo se les asocia con estilos de riesgo, sino que se les atribuyen identidades de riesgo (Abbasi,Rafique, Aziz y Hussai, 2013).

Identidad y estigma son dos procesos psicosociales que para fines del presente trabajo serán entendidos como atribuciones y elecciones sesgadas a favor de un grupo de pertenencia con respecto a otro grupo de referencia (Cañizo y Salinas, 2010). 


\section{$\underline{\text { http://revistainvestigacionacademicasinfrontera.com }}$}

Ambas definiciones subyacen de considerar al VIH/SIDA como un problema de salud pública, la cual cobra sentido en un contexto; económico, político, social, asistencial, simbólico, institucional, organizacional, profesional (véase tabla 1).

Tabla 1. Contexto social de la salud pública

\begin{tabular}{|c|c|c|c|c|}
\hline Contexto & Dimensiones & Factores & Intervenciones & Indicadores \\
\hline \multirow[t]{2}{*}{ Político } & \multirow[t]{2}{*}{ Compromiso } & \multirow[t]{2}{*}{$\begin{array}{l}\text { Construcción de } \\
\text { agenda }\end{array}$} & \multirow[t]{2}{*}{$\begin{array}{l}\text { Establecimiento de } \\
\text { convenios }\end{array}$} & \multirow{2}{*}{$\begin{array}{lr}\text { Porcentajes de } r \text { acue } \\
\text { establecidos } & \mathrm{s} \\
\text { condicionantes } & \text { sociales } \\
\text { locales } & \\
\end{array}$} \\
\hline & & & & \\
\hline Simbólico & $\begin{array}{l}\text { Normas, } \\
\text { significados, } \\
\text { ideologías, visiones }\end{array}$ & $\begin{array}{l}\text { Poder, estigma, } \\
\text { discriminación, } \\
\text { influencia }\end{array}$ & $\begin{array}{l}\text { Mediatización, } \\
\text { encuadre, } \\
\text { sensibilización, } \\
\text { defensoría, } \\
\text { transformación }\end{array}$ & $\begin{array}{l}\text { Porcentajes en torno a } \\
\text { creencias relacionadas con la } \\
\text { acción del otro más cercano }\end{array}$ \\
\hline Material & Economía, praxis & $\begin{array}{l}\text { Pobreza, } \\
\text { capacidades, } \\
\text { criminalización }\end{array}$ & $\begin{array}{l}\text { Producción, } \\
\text { redistribución, } \\
\text { capacidad, }\end{array}$ & $\begin{array}{l}\text { Porcentajes de exclusión y } \\
\text { marginalidad asistencial }\end{array}$ \\
\hline Relacional & $\begin{array}{l}\text { Intra e inter- } \\
\text { comunidades, } \\
\text { entidades, instancias }\end{array}$ & $\begin{array}{l}\text { Capitales, } \\
\text { participación }\end{array}$ & $\begin{array}{l}\text { educación, } \\
\text { iniciativas, } \\
\text { movilización }\end{array}$ & $\begin{array}{l}\text { Porcentajes de organización y } \\
\text { participación consultiva, } \\
\text { deliberativa o consensual }\end{array}$ \\
\hline Institucional & $\begin{array}{l}\text { Estructura, } \\
\text { Incidencia, } \\
\text { prevalencia }\end{array}$ & $\begin{array}{l}\text { Vulnerabilidad, } \\
\text { marginalidad, } \\
\text { exclusión }\end{array}$ & $\begin{array}{l}\text { Atención } \\
\text { especializada, } \\
\text { tratamiento } \\
\text { focalizado }\end{array}$ & $\begin{array}{l}\text { Establecimiento de costos y } \\
\text { financiamientos, estructura } \\
\text { hospitalaria e instalaciones } \\
\text { modernas, mortalidad, } \\
\text { orfandad y riesgos; porcentaje } \\
\text { de casos en sectores específicos } \\
\text { diagnosticados } \\
\text { procedimientos estandarizados }\end{array}$ \\
\hline Organizacional & $\begin{array}{l}\text { Prestación, } \\
\text { capacidad, calidad }\end{array}$ & $\begin{array}{l}\text { Clima } \quad \text { de } \\
\text { relaciones y tareas }\end{array}$ & $\begin{array}{l}\text { Reingeniería, } \\
\text { sinergia }\end{array}$ & $\begin{array}{l}\text { Alianzas estratégicas en cuanto } \\
\text { a formación de voluntariado, } \\
\text { procesos de gestión y } \\
\text { promoción, Porcentaje de } \\
\text { solicitantes de diagnóstico y } \\
\text { seguimiento de casos, } \\
\text { comunicación de riesgos y } \\
\text { promoción de la salud }\end{array}$ \\
\hline Asistencial & $\begin{array}{l}\text { Conocimiento, } \\
\text { comportamiento, } \\
\text { adherencia, } \\
\text { representación, } \\
\text { felicidad, influencia }\end{array}$ & $\begin{array}{l}\text { Promoción, } \\
\text { gestión, calidad de } \\
\text { vida y bienestar } \\
\text { subjetivo }\end{array}$ & $\begin{array}{l}\text { Canalización, } \\
\text { seguimiento, } \\
\text { mediación, } \\
\text { promoción, gestión }\end{array}$ & $\begin{array}{l}\text { Porcentaje de autocuidado y } \\
\text { afrontamiento en torno a la } \\
\text { problemática, formación de } \\
\text { actitudes positivas }\end{array}$ \\
\hline
\end{tabular}

Fuente: Mannell, Comish y Rusell (2014) 


\section{http://revistainvestigacionacademicasinfrontera.com}

En referencia a las expectativas, la identidad es una consecuencia de una elección deliberada, planificada y sistemática (Summer, 2011). En este sentido, son tres los marcos teóricos actitudinales que explicaría el favoritismo del endogrupo en detrimento del exogrupo conocido como etnocentrismo, aunque un conflicto al interior del grupo de pertenencia generaría un altercentrismo (Chacón, Barrantes, Comerfold y McCoy, 2014).

La Teoría de la Acción Razonada (TAR) sostendría que la identidad y el estigma son productos de un procesamiento de información generalizado sobre un grupo de pertenencia en contraste con las atribuciones a un grupo de referencia (Ferragut y Ortiz, 2013). En este modelo conceptual, las creencias procesan la información circundante, pero son las actitudes quienes determinarán la elección sesgada de un grupo (Uribe y Orcasita, 2011). Se trata de categorías en las que la información es concentrada para llevar a cabo una acción específica que enaltezca al endogrupo y soslaye al exogrupo (García y Rodríguez, 2014).

Sin embargo, la acción deliberada resultante, categorizada de información general, no siempre anticipa comportamientos específicos y más bien requerirá de percepciones de control o controles conductuales percibidos (Jouen y Zielinski, 2013).

Es así como la Teoría del Comportamiento Planificado (TCP) supone que sólo la información delimitada y su procesamiento, tanto de creencias como de percepciones especificarán la información de un modo tal que anticiparían comportamientos puntuales (Klaus, Piñeres y Hincapie, 2010).

De este modo, la TAR y TCP, identidad y estigma son consecuencias de haber procesado deliberada, planificada y sistemática información concerniente a un grupo muy cercano a un individuo después de haber sido contrasta con información relativa a otros grupos lejanos a ese mismo individuo (Rodríguez, 2013). 


\section{http://revistainvestigacionacademicasinfrontera.com}

No obstante que las actitudes han sido consideradas como asociaciones entre evaluaciones hechas a partir de categorías grupales, la Teoría del Procesamiento Espontáneo (TPE) sostiene que son más bien las actitudes procesos arbitrarios, espontáneos o semiautomáticos (Albacerrin y Wyer, 2011).

La TPE, a diferencia de la TAR y la TCP que plantean un proceso deliberado, planificado y sistemático, considera que esta información se resguarda en la memoria a largo y corto plazo, así como en su fase procedimental (Mardones y Guzmán, 2011). De esta forma, la información se almacena y está en un estado de latencia que se activará cuando algún estímulo la recupera y asocia con un comportamiento improvisado (Hughes y Barnes, 2011).

La identidad y el estigma, desde la óptica de la TPE, son parte del proceso arbitrario, espontáneo o semiautomático que caracteriza a las actitudes (Solat,Velhal, Mahajan, Rao y Sharma, 2012). En ese sentido, se advierte que la identidad es una actitud negativa o positiva, a favor o en contra de un grupo y el estigma es una evaluación sesgada de dicho proceso actitudinal e identitario, pero que por algún motivo está latente y no se materializa como un comportamiento hasta que un estímulo reactiva la discrecionalidad del individuo por categorizar a grupos relacionados con portadores de una enfermedad como el VIH/SIDA (Becerra, Chunga, Palomino, Arévalo, Nivin, Portocarrero, Carbajal, Tomás, Caro, Astocaza, Torres, Carbajal, Pinto, Moras, Munayco y Gutiérrez, 2012)

A partir de la TAR, TCP y TPE es posible construir un marco teórico en el que coexisten tanto los procesos deliberados con los espontáneos, planificados con discrecionales, sistemáticos con semiautomáticos (Selesho y Modise, 2012). En este modelo, la información no fluye de un lado hacia otro o se interconecta de un extremo a otro, sino que está en toda la estructura cognitiva del individuo evidenciando la formación de una red (Villa, 2010). 


\section{http://revistainvestigacionacademicasinfrontera.com}

La Teoría de la Red Actitudinal (TRA) sostiene que tanto la identidad como el estigma no sólo están correlacionadas con las actitudes, sino además son nodos estructurales desde los que la información se resignifica hasta formar nuevos nodos; asociaciones entre categorías y evaluaciones en torno a información concerniente al endogrupo y exogrupo (Méndez, Rojas y Moreno, 2012).

Los estudios psicológicos de las actitudes, la identidad y el estigma plantean una red cognitiva para explicar las relaciones entre grupos y portadores de VIH/SIDA (Castillo y Chinchilla, 2011).

Petro (2013) considera que la red cognitiva es un proceso de responsabilidad social en la que los portadores no sólo evidencian un auto-cuidado, sino además diseminan sus experiencias a fin de prevenir re-infecciones o contagios que deriven en un problema de salud pública. Giraldo (2013) encontró en la expresividad de la enfermedad una estructura de red asociada a la responsabilidad social y la solidaridad con portadores en fase terminal, pero Méndez (2013) evidenció una red de símbolos determinante del reclutamiento de víctimas de explotación sexual que desarrollaron comportamientos de minusvaloración, riesgo y reincidencia.

Entre las conductas sexuales de riesgo está el coito interruptus que Petracci (2011) relacionó con una red de creencias acerca de invulnerabilidad de los jóvenes con respecto al contagio del VIH o el no desarrollo del SIDA. En este sentido, Serrano (2011) advierte que cuando las parejas establecen una red comunicativa, sus decisiones se llevan a cabo por consenso, pero cuando sólo se establece una comunicación unidireccional, los hombres delegan en la mujer la responsabilidad de la anticoncepción. Por su parte, Hernández (2013) descubrió que cuando un grupo es explotado por proxenetas, éstos últimos establecen discursos que legitiman la superioridad de los residentes u oriundos con respecto a migrantes. 


\section{http://revistainvestigacionacademicasinfrontera.com}

En este mismo sentido, Aramayo (2011) mediante un inventario de experiencias de agresión sexual estableció un vínculo con las experiencias sexuales actuales, pero Rivers (2011) encontró que las víctimas no siempre se consideran explotadas y más bien son sus creencias religiosas en torno al pecado las que inciden en sus comportamientos sexuales.

Las dimensiones psicosociales de grupos cercanos a portadores de VIH/SIDA se circunscriben a un contexto de salud pública, en torno al cual se genera información relativa a estilos de vida, conductas de riesgo, violencia y explotación sexual (Villegas, Rosas y García, 2018)

La identidad y el estigma reportados en el estado del conocimiento respecto a grupos cercanos a portadores de VIH/SIDA: no sólo serían factores preponderantes en su estudio, sino además serían efectos psicosociales de la información relativa a estilos de vida y conductas de riesgo, violencia y explotación sexual diseminados en las percepciones, creencias, actitudes y discursos de grupos con los que familiares y amigos de portadores de VIH/SIDA interactúan (Delgado, Méndez, Morales, García, Mendoza y Vilchis, 2018).

En este sentido, tanto la identidad como el estigma son dos nodos representativos y discursivos a partir de los cuales se procesa la información concerniente a los riesgos de salud pública. Es decir, la información atribuida a grupos vulnerables al VIH/SIDA justifica y legitima la división sexual entre aquellos grupos que deliberan, planifican y sistematizan sus coitos ante los grupos que arbitraria e improvisadamente tienen encuentros sexuales (Carreón. Hernández, Bustos y García, 2017). 


\section{http://revistainvestigacionacademicasinfrontera.com}

\section{Método}

Diseño. Se llevo a cabo un estudio exploratorio, transversal y correlacional.

Muestra. Se realizó una selección no probabilística de 258 estudiantes de una universidad pública del Estado de México. El criterio de elección fue tener un conocimiento suficiente del VIH/SIDA y haber interactuado con portadores, sus familiares o amistades.

Sexo. El 49\% de los encuestados fueron mujeres $(M=339,45$ dólares de ingreso mensual y $D E=21,37$ dólares $)$, el $48 \%$ fueron hombre $(M=384,58$ dólares y $D E=19,36$ dólares $)$ y el $3 \%$ no contestó

Edad. El 51\% tiene entre 22 y 29 años $(M=326,38$ dólares de ingreso mensual y $D E=$ $21,25)$, el $37 \%$ tiene entre 18 y 22 años $(M=273,29$ y $D E=18,0)$, el $9 \%$ tienen menos de 18 años $(M=220,13$ y $D E=10,6)$, el 3\% no contestó

Grupo. El 63\% declaró que no pertenecía a algún grupo en especial $(M=257,27$ dólares de ingreso mensual y $D E=19,08)$, el $34 \%$ señaló que si pertenecía a un grupo en particular ( $M$ $=345,24$ y $D E=17,20)$, el $3 \%$ no contestó

Preferencias. El 82\% señaló que es de preferencia heterosexual ( $M=259,40$ dólares de ingreso mensual y $D E=37,29)$, el $15 \%$ se declaró homosexual $(M=301,27$ y $D E=18,79)$, el $3 \%$ no contestó

Coito. El 71\% declaró que tuvo relaciones sexuales con personas de diferente sexo antes de los 18 años $(M=241,28$ dólares de ingreso mensual y $D E=17,29)$, el $20 \%$ no ha tenido relaciones sexuales $(M=215,01$ y $D E=18,20)$, el 6\% señaló que tuvo relaciones sexuales con personas del mismo sexo $(M=253,48$ y $D E=15,08)$ 


\section{http://revistainvestigacionacademicasinfrontera.com}

Fuentes. El 71\% dijo que se enteró del VIH/SIDA en la televisión ( $M=267,28$ dólares de ingreso mensual y $D E=17,68)$, el $20 \%$ señaló que se enteró en la escuela $(M=283,49$ y $D E$ $=18,39)$, el 6\% declaró que no sabía en qué consistía la enfermedad de transmisión sexual $(M=254,71$ y $D E=18,29)$

Instrumento. Se utilizó la Escala de Expectativas hacia el VIH/SIDA de autista, Aldana y García (2018) la cual incluye 26 aseveraciones en torno a disposiciones negativas o positivas, favorables o desfavorables hacia grupos cercanos a portadores de VIH/SIDA y sus estilos de vida, conductas de riesgos y vulnerabilidad a la explotación sexual. Cada aseveración incluye cuatro opciones de respuesta que van desde $0=$ "nada probable" hasta $3=$ muy probable. La dimensión de identidad mide las expectativas hacia un grupo cercano a portadores de VIH/SIDA en comparación a grupos que se consideran distantes y alcanzo una confiabilidad $($ alfa $=0,718)$ superior a la mínima indispensable. La dimensión de estigma mide las expectativas hacía los estilos de vida y conductas de riesgo, así como la vulnerabilidad a la explotación sexual asociada con grupos cercanos a portadores de VIH/SIDA con respecto a grupos distantes alcanzando una confiabilidad (alfa $=0,702)$ superior a la requerida. La dimensión de seguridad mide las expectativas hacia los beneficios de interactuar con grupos cercanos a portadores del VIH / SIDA La escala general tuvo una consistencia interna (alfa $=0,780$ ) superior a las subescalas de identidad y estigma.

Procedimiento. Se ajustó el instrumento original al ámbito universitario considerando los hallazgos reportados en el estado del conocimiento y el contexto de salud pública. Se encuestaron a los estudiantes en el vestíbulo de los servicios médicos y orientación sexual previo consentimiento informado y advertencia de que los resultados del estudio no afectarían su estatus académico. Los datos se procesaron en el SPSS versión 20 y AMOS versión 4,0 


\section{http://revistainvestigacionacademicasinfrontera.com}

Análisis. Se estimaron medidas de tendencia central y medidas de dispersión para los datos descriptivos del instrumento y coeficientes alfa para la confiabilidad, así como valores de análisis factorial exploratorio de ejes principales con rotación promax, adecuación y esfericidad. Los valores superiores a 0,70 fueron considerados como evidencia de consistencia interna y los valores KMO superiores a 0,600 fueron asumidos como evidencia de adecuación con niveles significativos menores a 0,05 se consideraron caso de esfericidad. Los pesos factoriales superiores a 0,300 se asumieron como evidencia de validez de constructo.

\section{Resultados}

La Tabla 2 muestra valores superiores a 0,70 para los ítems que se midieron por tres subescalas relativas la identidad, el estigma y la seguridad como factores preponderantes de las expectativas hacia grupos cercanos a portadores del VIH/SIDA: la cual se estableció con pesos factoriales superiores a 0,300 mismos que explicaron el $23 \%$, el $17 \%$ y $12 \%$ de la varianza total.

Tabla 2. Propiedades psicométricas del instrumento

\begin{tabular}{|c|c|c|c|c|c|c|c|c|}
\hline $\mathbf{R}$ & $M$ & $D$ & $\mathbf{S}$ & C & $\mathbf{A}$ & F1 & F2 & F3 \\
\hline R1 & 2,48 & 0,17 & 1,23 & 1,32 & 0,713 & 0,482 & & \\
\hline R2 & 2,30 & 0,13 & 1,45 & 1,45 & 0,729 & 0,493 & & \\
\hline R3 & 2,94 & 0,18 & 1,39 & 1,87 & 0,794 & 0,493 & & \\
\hline R4 & 2,60 & 0,09 & 1,32 & 1,09 & 0,739 & 0,491 & & \\
\hline R5 & 2,64 & 0,11 & 1,31 & 1,89 & 0,712 & 0,402 & & \\
\hline R6 & 2,83 & 0,10 & 1,54 & 1,56 & 0,739 & 0,536 & & \\
\hline R7 & 2,49 & 0,13 & 1,76 & 1,02 & 0,725 & 0,406 & & \\
\hline
\end{tabular}


Año 11.

Revista de Investigación

Núm. 28

\section{$\underline{\text { http://revistainvestigacionacademicasinfrontera.com }}$}

\begin{tabular}{|c|c|c|c|c|c|c|c|}
\hline R8 & 2,83 & 0,15 & 1,98 & 1,25 & 0,739 & 0,514 & \\
\hline R9 & 2,96 & 0,94 & 1,67 & 1,43 & 0,748 & 0,578 & \\
\hline R10 & 2,77 & 0,85 & 1,12 & 1,53 & 0,745 & 0,351 & \\
\hline R11 & 2,49 & 0,71 & 1,34 & 1,87 & 0,741 & 0,362 & \\
\hline R12 & 2,61 & 0,39 & 1,32 & 1,67 & 0,756 & 0,462 & \\
\hline R13 & 2,84 & 0,31 & 1,12 & 1,31 & 0,772 & 0,468 & \\
\hline R14 & 2,90 & 0,48 & 1,54 & 1,46 & 0,704 & 0,591 & \\
\hline R15 & 1,04 & 0,57 & 1,56 & 1,65 & 0,714 & 0,493 & \\
\hline R16 & 1,05 & 0,26 & 1,78 & 1,03 & 0,726 & 0,491 & \\
\hline R17 & 1,92 & 0,83 & 1,94 & 1,43 & 0,701 & & 0,384 \\
\hline R18 & 1,06 & 0,93 & 1,34 & 1,32 & 0,735 & & 0,412 \\
\hline R19 & 1,07 & 0,99 & 1,32 & 1,57 & 0,794 & & 0,485 \\
\hline R20 & 1,01 & 0,80 & 1,24 & 1,39 & 0,752 & & 0,384 \\
\hline $\mathbf{R 2 1}$ & 1,82 & 0,74 & 1,14 & 1,32 & 0,734 & & 0,461 \\
\hline R22 & 1,16 & 0,69 & 1,15 & 1,31 & 0,705 & & 0,401 \\
\hline R23 & 1,19 & 0,36 & 1,49 & 1,13 & 0,772 & & 0,493 \\
\hline R24 & 1,06 & 0,46 & 1,03 & 1,14 & 0,785 & & 0,524 \\
\hline
\end{tabular}

$\mathrm{R}=$ Reactivo, $\mathrm{M}=$ Media, $\mathrm{D}=$ Desviación Estándar, $\mathrm{S}=$ Sesgo, $\mathrm{C}=$ Curtosis, Bootstrap = 0,000; Curtosis Multivariante $=1,304 ; \mathrm{KMO}=0,721$; BARTLETT $\left[\chi^{2}=18,33(18 \mathrm{gl}) \mathrm{p}=\right.$ 0,000], Método: Ejes principales, Rotación: Promax. F1 = Expectativas de Identidad de grupos cercanos a portadores de VIH /SIDA (23\% de la varianza total explicada), F2 = Expectativas de Estigma de grupos cercanos a portadores de VIH / SIDA (17\% de la varianza explicada), F3 = Expectativas de Beneficios al interactuar con grupos cercanos a portadores de VIH / SIDA (12\% de la varianza total explicada)

Fuente: Elaborada con los datos del estudio 


\section{http://revistainvestigacionacademicasinfrontera.com}

La consistencia interna y la validez de constructo señalan que el instrumento puede ser replicado en otros contextos con otras muestras, pero éstas últimas deberán ser estudiantes universitarios ya que la selección de la muestra no fue probabilística.

Una vez establecidos los tres factores se procedió a estimar y a analizar sus relaciones lineales con la finalidad de indagar la estructura que ajusta a las relaciones teóricas reportadas en la literatura del estado del conocimiento (véase Tabla 3).

Tabla 3. Correlaciones y covarianzas entre los factores

\begin{tabular}{lllllll}
\hline & F1 & F2 & F3 & F1 & F2 & F3 \\
\hline F1 & 1,00 & & & 1,90 & & \\
\hline F2 &, $354 * * *$ & 1,00 & &, 325 & 1,78 & \\
\hline F3 &, $412^{* *}$ &, $437 *$ & 1,00 &, 436 &, 438 & 1,85 \\
\hline
\end{tabular}

$\mathrm{F}=$ Factor: $* \mathrm{p}<, 01 ;{ }^{* * *} \mathrm{p}<, 001 ; * * * \mathrm{p}<, 001$

Fuente: Elaborada con los datos del estudio

Con la intención de observar la estructura de trayectorias reflejantes se llevó a cabo la estimación del modelo en el que es posible advertir que prevalecen tres dimensiones vinculadas a seis indicadores cada uno (véase Figura 1).

Figura 1. Estructura factorial exploratoria de las expectativas hacia grupos cercanos a portadores de VIH / SIDA 
Núm. 28

ISSN: 2007-8870

\section{http://revistainvestigacionacademicasinfrontera.com}

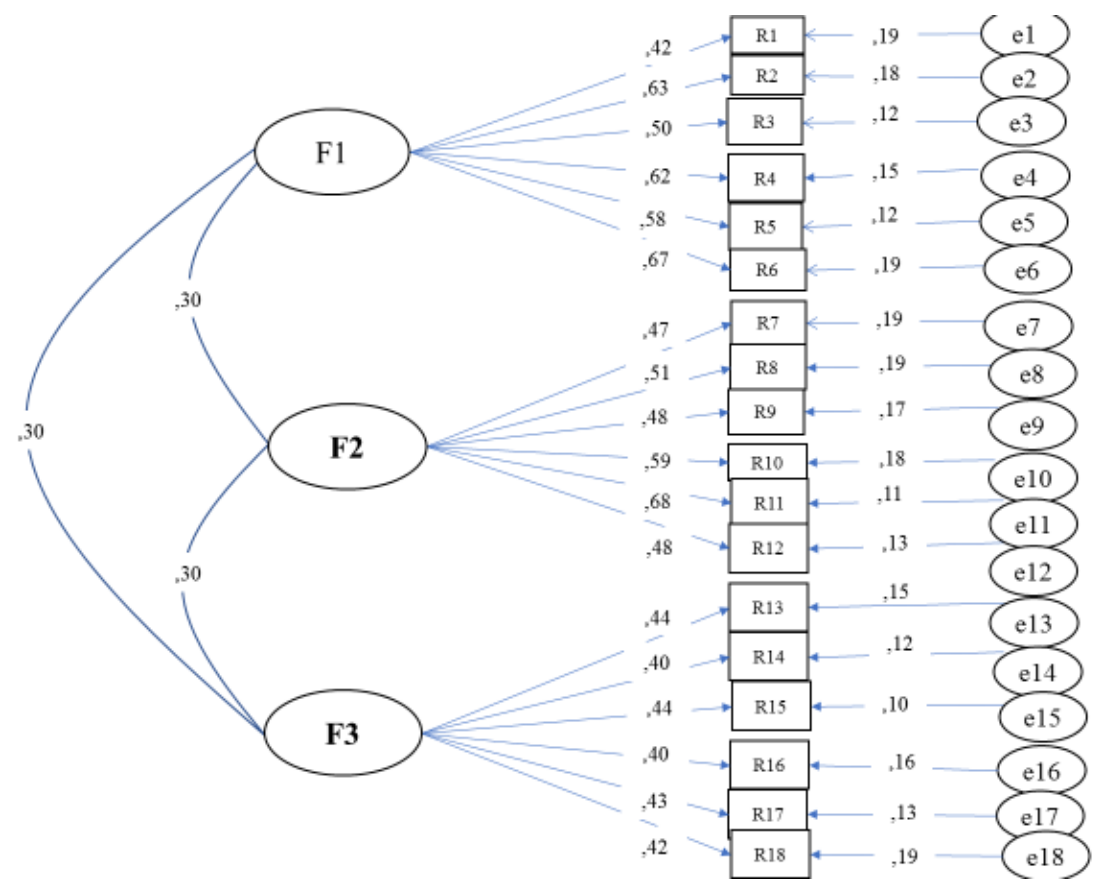

$\mathrm{F}=$ Factor, $\mathrm{R}=$ Reactivo, $\mathrm{e}=$ Error de Medición: $\cap$ relación factorial, $\leftarrow$ trayectoria lineal causal, $\rightarrow$ trayectoria lineal reflejante

Fuente: Elaborada con los datos del estudio

Los valores de los parámetros de ajuste y residual $\left\lceil\chi^{2}=324,3\right.$ (35 gl) p <,010; GFI = ,990; CFI = ,997; RMSEA =,008 $\mathrm{J}$ sugieren el no rechazo de la hipótesis nula relativa a las diferencias significativas entre las relaciones teóricas de las expectativas con respecto a las relaciones empíricas encontradas.

\section{Discusión}

El presente estudio ha establecido la validez y confiabilidad de un instrumento que mide las expectativas hacia la identidad y el estigma de grupos cercanos a portadores de VIH/SIDA en un contexto en el que los medios de comunicación, principalmente la televisión fue 


\section{http://revistainvestigacionacademicasinfrontera.com}

asumida como la fuente informativa más preponderante en cuanto a estilos de vida y conductas de riesgo, así como la vulnerabilidad a la explotación sexual por parte de quienes interactúan con portadores de VIH/SIDA.

Sin embargo, el reporte de Afanador (2014) advirtió un sesgo relativo a la identidad de género al momento de la plática sexual entre padres e hijos y concluyó que no sólo el tema sexual era un tabú, sino que además estaba orientado por una visión de género femenina más que una identidad de género masculina. En este sentido, el presente estudio advierte que la identidad de género estaría vinculada con el estigma, ya que se trata de dos nodos informativos que si bien fueron influenciados por medios de comunicación orientan la formación de expectativas hacia la elección y preferencia de un grupo heterosexual con respecto a un grupo homosexual.

De este modo, Hurtado, Avandaño y Moreno (2013) sostienen que los adolescentes que inician sus relaciones sexuales están más influidos por sus pares que por sus padres, profesores, grupos sociales o redes digitales. Es decir, la identidad parece ser un proceso que explicita no sólo la preferencia sexual, sino además la práctica y la frecuencia de la misma al momento de improvisar o planificar un acto sexual. En el presente estudio sólo se estableció que los encuestados no sólo distinguen su grupo de pertenencia al grupo de referencia en cuestión (familiares y amigos de VIH/SIDA), sino además advierten una tendencia de atributos que los hace evaluar a esos grupos como diferentes al asociarles estilos de vida y conductas de riesgo propios de un sector vulnerable a la explotación sexual.

Por último, con respecto a la estudio de García (2013) en el que el grupo de profesionales de la salud estigmatizaron la atención a familiares y portadores de VIH/SIDA como un grupo vulnerable al que se le debiera de atender de un modo diferente a los demás grupos de familiares y enfermos, el presente trabajo considera que la identidad no sólo es evaluada por 


\section{http://revistainvestigacionacademicasinfrontera.com}

los encuestados, sino además está vinculada con asociaciones que ubican a grupos vulnerables en prácticas de riesgo y explotación sexual.

Sin embargo, el presente trabajo no explica cómo es que la identidad y el estigma son nodos de atribución de información concerniente a estilos de vida y conductas de riesgo en un entorno de explotación sexual, pero si evidencia que tanto la identidad como el estigma son componentes de un constructo relativo a las expectativas hacia grupos relacionados con portadores de VIH/SIDA. Es decir, el estudio podrá o no comprobar que la identidad y el estigma son nodos en donde se concentra o genera la información, pero abre la discusión en torno a la importancia de observar la relación entre grupos vulnerables, marginados o excluidos en torno a portadores del VIH/SIDA ya que estos son parte de un soporte social que determina en buena medida la adherencia al tratamiento.

\section{Conclusión}

El aporte del presente trabajo al estado del conocimiento es haber establecido la validez y confiabilidad de un instrumento que mide dos factores psicosociales preponderantes en la formación de expectativas hacia grupos cercanos a portadores de VIH/SIDA. De acuerdo con la Teoría del Procesamiento Espontáneo, la memoria no sólo resguarda información concerniente al VIH/SIDA, estilos y conductas de riesgo de grupos vulnerables, sino además tal información es activada espontánea o arbitrariamente para llevar a cabo conductas improvisadas que explicarían el autocuidado. En este sentido, identidad ye estigma serían resultado de la información difundida en los medios, pero indicarían la emergencia de un proceso psicosocial relativo al poder o la influencia social en torno a la sexualidad. 


\section{http://revistainvestigacionacademicasinfrontera.com}

\section{Referencias}

Abbasi, A., Rafique, M., Aziz, W. y Hussai, W. (2013). Human immunodeficiency virus / acquired immune deficiency syndrome (HIV/AIDS): Knowledge, attitudes of university students of the state of Azad Kashmir (Pakistan). Journal of AIDS \& HIV Research, 5, 157-162

Afanador, A. (2014). Particularidades con respecto a la formación de la sexualidad en los adolescentes. Cuadernos Hispanoamericanos de Psicología, 13 (2), 91-104

Albacerrin, D. y Wyer, R. (2011). Elaborative and non elaborativeproccess a behaviorrelatedcommunication. Personality and Social PsychologyBulleting, 27, 691705

Anguiano, F., Aldana, W. I., Valdés, O., Delgado, M. A. y García, C. (2018). Estructura factorial exploratoria de una escala de actitud hacia grupos cercanos a portadores del VIH / SIDA. Limite, 13 (42), 41-64

Aramayo, S. (2011). Terapia centrada en las soluciones aplicadas a la agresión sexual. Estudio de caso. Revista Ajayu, 9, 132-168

Bautista, M., Aldana, W. I. y García, C. (2018). Análisis de expectativas de adhesión al tratamiento del Virus de Inmunodeficiencia Humana (VIH) en estudiantes de una universidad pública. Perspectivas, 20 (1), 53-70

Becerra, V., Chunga, N., Palomino, C., Arévalo, T., Nivin, J., Portocarrero, L., Carbajal, P., Tomás, B., Caro, M., Astocaza, L., Torres, L., Carbajal, E., Pinto, A., Moras, M., Munayco, M. y Gutiérrez, C. (2012). Asociación entre conocimiento de mujeres 


\section{http://revistainvestigacionacademicasinfrontera.com}

peruanas hacia VIH y sus actitudes frente a personas infectadas. Revista Peruana de Epidemiología, 16, 1-8

Cañizo, E. y Salinas, F. (2010). Conductas sexuales alternas y permisividad en jóvenes universitarios. Enseñanza e Investigación en Psicología. 15, 285-309

Carreón. J., Hernández, J., Bustos, J. M. y García, C. (2017). Confiabilidad y validez de un instrumento que mide el compromiso laboral de trabajadoras sociales en instituciones de asistencia sanitaria. Encrucijada, 26, 1-10

Castillo, A. y Chinchilla, Y. (2011). La experiencia de la escuela de psicología de la Universidad de Costa Rica en la atención de la explotación sexual comercial. Revista Latinoamericana de Derechos Humanos, 22, 121-151

Chacón, M., Barrantes, K., Comerfold, M. y McCoy, C. (2014). Prácticas sexuales y conocimiento sobre el VIH/SIDA entre usuarios de drogas en una comunidad de bajos ingresos en Costa Rica. Salud y Drogas, 14 (1), 27-36

Davis, M., Shell, A. y King, S. (2012). Assessing pharmacist' perspectives of HIV and the care of HIV-infected patients in Alabama. Pharmacy Practice, 10, 188-193

Delgado, M. A., Méndez, A., Morales, M. L., García, C., Mendoza, D. y Vilchis, F. J. (2018). Contraste de un modelo de disposición a la solicitud de interrupción del embarazo. Eurytmie, 5 (1), 1-13

Ferragut, M. y Ortiz, M. (2013). Psychological values as protective factors against sexist attitudes in preadolescents. Psicothema, 25, 38-52 


\section{http://revistainvestigacionacademicasinfrontera.com}

García, C. (2013). Actitud de trabajadoras sociales hacia portadores del Virus de Inmunodeficiencia Humana en centros de salud comunitaria. Salud \& Sociedad, 4 (1), $60-68$

García, C. (2018). Formación autonómica en la interrupción del embarazo. Nómadas, 55, 112

García, I. y Rodríguez, M. (2014). Situación en que viven y adhesión al tratamiento en mujeres y jóvenes de San Luis Potosí con VIH/SIDA. Acta Universitaria, 24 (4), 3-14

García, J. J., Delgado, M. A. y García, C. (2018). Confiabilidad y validez de un instrumento que mide el bienestar sanitario. Eureka, 15 (2), 1-11

Giraldo, I. (2013). Cibercuerpos: los jóvenes y sexualidad en la posmodernidad. Actualidades Investigativas en Educación, 13, 1-22

Hernández, I. (2013). Haciendo camino al andar: Migración, feminización y trata de personas en los flujos de migración irregular en la frontera sur de México. Revista Digital Universitaria, 14, 1-15

Hughes, S. y Barnes, D. (2011). The dominance of associative theorizing in implicit attitude research: propositional and behavioral alternatives. Psychological Research, 6, 465498

Hurtado, N., Avandaño, M. y Moreno, F. (2013). Embarazo en la adolescencia: entre el fracaso informativo y el logro psíquico. Revista de Psicología de la Universidad de Antioquia, 5 (1), 93-102 


\section{http://revistainvestigacionacademicasinfrontera.com}

Jouen, F. y Zielinski, S. (2013). La explotación sexual comercial de menores en los destinos turísticos. Conocimientos, actitudes y prevención de los prestadores de servicios turísticos en Tananga, Colombia. Revista de Turismo y Patrimonio Cultural, 11, 121134

Klaus, A., Piñeres, J. y Hincapie, A. (2010). Subjetivaciones lenguaje y parodia: reflexiones en torno a los discursos expertos sobre la explotación sexual comercial de niños y niñas adolescentes. Revista Latinoamericana de Ciencias Sociales, Niñez y Juventud, 8, 269291

Mannell, J., Cornish, F. y Russell, J. (2014). Evaluating social outcomes of HIV/AIDS interventions: a critical assessment of contemporary indicators frameworks. Journal of International AIDS society. 17 (1), 1-11 [DOI: 10.7448/IAS.17.1.19073]

Mardones, R. y Guzmán, M. (2011). Hacia un tratamiento integral desde el modelo psicosocial en niños, niñas y adolescentes explotados sexualmente. Revista Científica de Psicología, 2, 27-47

Méndez, M. (2013). Trata: esclavitud invisibilizada en Costa Rica. Estudio de cinco casos. Revista Costarricense de Psicología, 32, 109-135

Méndez, R., Rojas, M. y Moreno, D. (2012). Explotación sexual comercial infantil: las rutas de la vida del maltrato. Investigación y Desarrollo, 20, 450-47

Petro, B. (2013). Attitudes and views of teachers towards student sexual relationships in secondary school in Tanzania. AcademicResearch International, 4, 232-241 


\section{http://revistainvestigacionacademicasinfrontera.com}

Quintero, M. L., Valdés, O., Delgado, M. A. y García, C. (2018). Evaluación de un modelo de estrategias institucionales del autocuidado. Uso del condón y prevención en jóvenes universitarios. Salud Problema, 12 (23), 56-68

Rivers, M. (2011). Los usos de la trata en Centroamérica: migración, género y sexualidad. Anuario de Estudios Centroamericanos. 37, 87-103

Rodríguez, D. (2013). Enfermedad crónica avanzada, padecimiento psíquico y sistema general de la seguridad social en la salud. Revista de Psicología de la Universidad de Antioquia, 5 (1), 75-92

Selesho, J. y Modise, A. (2012). Strategy (ies) in daling with HIV / AIDS in ours schools: changing the lenses. Journal of Human Ecology, 38, 181-189

Solat, S., Velhal, G., Mahajan, H., Rao, A. y Sharma, B. (2012). Assesment of knowledge and attitude of rural population about HIV/AIDS in Raigad Distrit, India. Journal of Dental and Medical Science. 1, 31-45

Summer, L. (2011). The theory of planned behavior and the impact of the past behavior. International Business and Economic Research Journal, 10, 91-110

Uribe, A. y Orcasita, L. (2011). Evaluación de conocimientos, actitudes, susceptibilidad y autoeficacia frente al VIH / SIDA en profesionales de salud. Avances de Enfermería. $29,271-284$

Vilchis, F. J., Velez, S. S. y García, C. (2018). Especificación de un modelo para el estudio de la sexualidad consensuada. Atlante, 9, 1-33

Villa, E. (2010). Estudio antropológico en torno a la prostitución. Cuicuilco, 17, 157-179 
Año 11.

Revista de Investigación

Núm. 28

Académica sin Frontera ISSN: 2007-8870

\section{http://revistainvestigacionacademicasinfrontera.com}

Villegas, E., Rosas, F. J. y García, C. (2018). Social Works a towards quality of life and wellbeing subjective. International Journal of Research in Humanities and Social Studies, 5 (6), 35-48

\section{Como citar este articulo}

García-Lirios Cruz. Estructura factorial exploratoria de las expectativas hacia grupos cercanos a portadores del VIH/SIDA. RIASF. Núm. 28, Julio-diciembre (2018), ISSN 2007-8870. pp. xX-XX. 